\title{
Embolotherapy for Neuroendocrine Tumors
}

\author{
Gregory J. Nadolski, MD² Michael C. Soulen, MD ${ }^{1}$ \\ 1 Division of Interventional Oncology, Department of Radiology and Surgery, \\ Abramson Cancer Center, University of Pennsylvania, Philadelphia \\ 2 Division of Interventional Radiology, Department of Radiology, \\ Penn Image-Guided Interventional Laboratory, University of \\ Pennsylvania, Philadelphia
}

Dig Dis Interv 2019;3:e1.

\section{Retraction Notice}

The publisher regrets an error that the above article was published online with an incorrect open access CC BY-NC-ND license.
Address for correspondence Gregory J. Nadolski, MD, Perelman School of Medicine at the University of Pennsylvania, Department of Radiology, 3400 Spruce St., 1 Silverstein, Philadelphia, PA 19104 (e-mail: Gregory.Nadolski@uphs.upenn.edu).

For this reason, the article has been retracted and the correct version of the article can be found here: https://doi. org/10.1055/s-0039-1688517.
Issue Theme Neuroendocrine Tumors; Guest Editors, Gregory J. Nadolski, MD, MSc and Michael C. Soulen, MD, FSIR, FCIRSE 